\title{
Diaphragm and lung-preserving surgery with hyperthermic chemotherapy for malignant pleural mesothelioma: A 10-year experience
}

\author{
Marcello Carlo Ambrogi, PhD, ${ }^{\mathrm{a}}$ Pietro Bertoglio, MD, ${ }^{\mathrm{a}}$ Vittorio Aprile, MD, ${ }^{\mathrm{a}}$ Antonio Chella, MD, ${ }^{\mathrm{b}}$ \\ Stylianos Korasidis, MD, ${ }^{a}$ Gabriella Fontanini, PhD, ${ }^{\mathrm{c}}$ Olivia Fanucchi, MD, ${ }^{\mathrm{a}}$ Marco Lucchi, MD, ${ }^{\mathrm{a}}$ and \\ Alfredo Mussi, MD
}

\section{ABSTRACT}

Background: The best surgical treatment for malignant pleural mesothelioma is still under a debate, but recent evidence points toward a less-invasive approach to reduce morbidity and mortality. We reported our 10-year experience of a limited surgical approach associated with hyperthermic intrathoracic chemotherapy (HITHOC).

Material and Methods: Between 2005 and 2014, patients with epithelioid or biphasic malignant pleural mesothelioma were treated with lung-diaphragmpericardium-sparing pleurectomy associated with double-drug HITHOC; at least 3 cycles of adjuvant chemotherapy were then administered. The primary outcome examined was the feasibility of the procedure, whereas secondary outcomes were overall survival and disease-free interval.

Results: Among 49 patients, 41 were male. Median age was 68 years (35-76 years). Histology was epithelioid in 43 cases. Pathologic stage I, II, III, and IV occurred in $12,14,20$, and 3 cases, respectively. No intraoperative complications or postoperative mortality occurred, whereas morbidity rate was $46.9 \%$. Median hospital stay was 8 days (5-45 days). Actuarial median overall survival was 22 months and a 1-, 2-, and 5-year survival accounted for 79.6\%, 45.7\%, and 9.9\%, respectively. Disease-free survival after surgery was $62 \%, 37.5 \%$, and $18.5 \%$ at 1,2 , and 5 years, respectively. Risk factors analysis for overall survival confirmed a significant role for early stages, epithelioid histology, and fibrinogen serum levels.

Conclusions: Cytoreductive surgery associated with HITHOC and adjuvant chemotherapy appears feasible and safe, with no mortality and low morbidity. Preserving lung and diaphragmatic function might warrant an acceptable longterm outcome. (J Thorac Cardiovasc Surg 2018;155:1857-66)

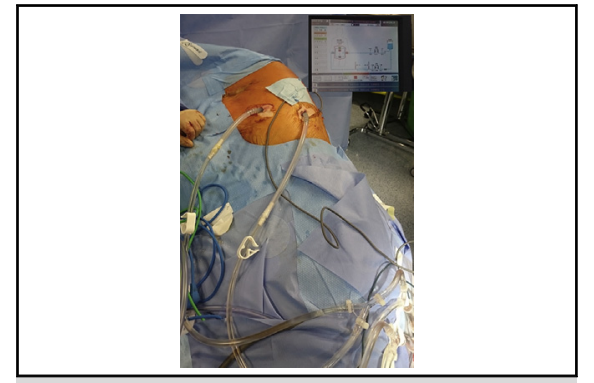

Lung and diaphragm-sparing surgery associated with hyperthermic intrathoracic chemotherapy leads to good long-term results.

\section{Central Message}

Using cytoreductive surgery with hyperthermic intrathoracic chemotherapy and adjuvant chemotherapy for malignant pleural mesothelioma, we preserved lung and diaphragmatic function, which might achieve acceptable long-term outcomes despite incomplete resection.

\section{Perspective}

The best surgical option for malignant pleural mesothelioma is still uncertain, but lung-sparing procedures are acquiring an increasing consensus. We report the results of a 10-year experience using pleurectomy and focal decortication associated with local hyperthermic chemotherapy with a total sparing of lung and diaphragmatic function and promising long-term oncologic outcomes.

See Editorial Commentary page 1867.

See Editorial page 1855.
Malignant pleural mesothelioma (MPM) is an aggressive disease arising from the mesothelial cells of the parietal pleura. Its incidence is strictly connected to direct or indirect asbestos exposure with a long latency period that can be up to 40 years $^{1}$; a peak number of cases of mesothelioma

\footnotetext{
From the ${ }^{\mathrm{a}}$ Division of Thoracic Surgery, Department of Surgical, Medical, Molecular Pathology and Critical Area, and ${ }^{\mathrm{b}}$ Division of Pneumonology, Cardio Vascular and Thoracic Department, University Hospital of Pisa, Pisa, Italy; and ${ }^{\mathrm{c}}$ Division of Pathological Anatomy, Department of Surgical, Medical, Molecular, and Critical Area Pathology, University of Pisa, Pisa, Italy.

Read at the 13th Congress of the International Mesothelioma Interest Group, Birmingham, United Kingdom, May 1-4, 2016.
}

is expected to occur in the next decade. Treatment for mesothelioma is still under debate: chemotherapy using cisplatin in association with pemetrexed has shown better results ${ }^{2}$ in controlling the disease; furthermore, different surgical approaches have been proposed. ${ }^{3}$ Usually, all the

Received for publication Sept 16, 2016; revisions received Sept 24, 2017; accepted for publication Oct 12, 2017; available ahead of print Nov 28, 2017.

Address for reprints: Pietro Bertoglio, MD, Division of Thoracic Surgery, Pisa University Hospital, via Paradisa 2 56100, Pisa (PI), Italy (E-mail: pieberto@ hotmail. com)

0022-5223/\$36.00

Copyright (c) 2017 by The American Association for Thoracic Surgery

https://doi.org/10.1016/j.jtcvs.2017.10.070 


$\begin{array}{ll}\text { Abbreviations and Acronyms } \\ \text { CI } & =\text { confidence interval } \\ \text { CT } & =\text { computed tomography } \\ \text { DFI } & =\text { disease-free interval } \\ \text { EPD } & =\text { extended pleurectomy and decortication } \\ \text { EPP } & =\text { extrapleural pneumonectomy } \\ \text { HITHOC } & =\text { hyperthermic intrathoracic } \\ & \text { chemotherapy } \\ \text { HR } & =\text { hazard ratio } \\ \text { MCR } & =\text { macroscopic complete resection } \\ \text { MPM } & =\text { malignant pleural mesothelioma } \\ \text { NLR } & =\text { neutrophil/lymphocyte ratio } \\ \text { OS } & =\text { overall survival } \\ \text { P/D } & =\text { pleurectomy and decortication } \\ \text { PLR } & =\text { platelet/lymphocyte ratio }\end{array}$

Uf $\begin{array}{ll}\text { Scanning this QR code will } \\ \text { take you to a procedural video } \\ \square \quad \text { and supplemental file. }\end{array}$

available therapies are used in a multimodality setting, but unfortunately none of them, both alone or combined, are able to warrant satisfactory long-term outcomes, and prognosis is still very disappointing. ${ }^{3}$

In particular, great debate regarding the role of surgery is currently ongoing. Although extrapleural pneumonectomy (EPP) was more extensively performed in cases of resectable MPM in the 1990s and at the beginning of the last decade, more recently pleurectomy and decortication (P/D) and extended pleurectomy and decortication (EPD) increasingly have been used. ${ }^{4}$ EPP accounts for an en-bloc resection of pleura, ipsilateral pericardium, hemidiaphragm, and the entire lung, whereas P/D and EPD allow sparing of lung parenchyma by the resection of parietal and visceral pleura with or without ipsilateral pericardium and hemidiaphragm. ${ }^{5}$ Despite no clear and consistent evidence, lung-sparing techniques might reduce the postoperative mortality and morbidity and increase the possibility for the patient to complete the multimodality treatment. Macroscopic complete resection (MCR) is usually considered the goal of surgery, ${ }^{6}$ but many reports describe similar long-term results in patients treated with chemotherapy alone or with nonradical surgery. ${ }^{7,8}$

Hyperthermic intrathoracic chemotherapy (HITHOC) combines the sensitizing effects of hyperthermia and the local effect of chemotherapy drugs; the local cytotoxic effects of chemotherapy are strengthened by the effect of the high temperature, which makes cancer cells more vulnerable to drugs, allowing a deeper penetration of chemotherapics. ${ }^{9}$
In thoracic surgery, HITHOC has been reported for the treatment of primary and secondary pleural tumors using different protocols, doses, and type of drugs. ${ }^{10-13}$

Since 2005, we started a new treatment protocol for MPM that consists of pleurectomy and partial decortication with HITHOC. This study reports our 10-year experience, focusing on feasibility, safety, long-term outcomes, and prognostic factors.

\section{MATERIALS AND METHODS}

All medical records of patients undergoing surgery and HITHOC for MPM in our institution during the period between March 2005 and December 2014 were reviewed. Approval for this retrospective study was obtained from our Institutional Ethical Committee. All patients gave full consent regarding data collection and its use in clinical studies; moreover, they gave their consent to update database information. Standardized perioperative care was used in all cases, as per protocol (Appendix E1). The results were then retrospectively collected.

The primary objective of this study was to confirm the feasibility of HITHOC immediately after partial pleurectomy by analyzing intraoperative complications, morbidity, and mortality particularly in regard to adverse events related to chemotherapy agents. The secondary objectives were to analyze long-term survival and to evaluate the pattern and timing of disease recurrence.

\section{Preoperative Assessment and Selection Criteria}

All patients had a histologic diagnosis of epithelial or biphasic MPM obtained via a thoracoscopic procedure. In no cases was pleurodesis using talc or any other chemical agent performed. All specimens were analyzed or verified by a dedicated team of pathologists, according to the World Health Organization criteria.

All patients affected by MPM who met inclusion criteria were treated following the same protocol and the same type of procedure during the study period at our institution; no alternative surgical procedures were offered to patients.

Selection criteria for surgery and HITHOC were clinical International Mesothelioma Interest Group stage I to III, age between 18 and 75 years, performance status $<3$ per the Eastern Cooperative Oncology Group scale, platelets count $>100,000 / \mathrm{L}$, hemoglobin level $>10 \mathrm{~g} / \mathrm{dL}$, white cell count $>4000 * 10^{3} / \mathrm{L}$, absence of cardiac or neuropathic diseases, and absence of concomitant infection or pregnancy. All patients were discussed by a multidisciplinary team; clinical N2 were excluded if a bulky lymphadenopathy or a multistation N2 disease was observed on the computed tomography (CT) scan. Invasive lymph node staging (namely endobronchial ultrasound or mediastinoscopy) was not required in our workup protocol.

In all cases, a chest radiograph and recent chest and abdomen CT scans were performed; conversely, positron emission tomography scanning was done only when required by the referring oncologist and not on a routine basis. Magnetic resonance imaging of the chest was performed only if a chest wall invasion was suspected on the CT scan or in cases of localized chest pain. Preoperative assessment consisted of complete blood analysis, D-dimer blood dosage, liver function tests, renal function tests, including creatinine clearance test, respiratory function tests, cardiological evaluation, including echocardiography, and lower-limb echo-Doppler.

To reduce the possibility of a renal impairment due to HITHOC, all patients received a standardized amount of fluid from the day before surgery until postoperative day $5(2000 \mathrm{~mL}$ the day before surgery, at least $3000 \mathrm{~mL}$ the day of surgery, and $2000 \mathrm{~mL}$ from postoperative day 1 until postoperative day 5), together with proton-pump inhibitors, diuretics, antibiotics, corticosteroids, and low-molecular-weight heparin. 


\section{Surgical Technique}

A posterior-lateral thoracotomy is routinely performed at the fifth/sixth intercostal space. The operative procedure consists of a complete parietal and mediastinal pleurectomy and the resection of the greater lesions on the visceral pleura; diaphragm and pericardium are always spared, with the aim of achieving an MCR or at least an extensive debulking with minimal impairment of the lung function. Lymph node sampling was routinely performed. At the end of the surgical resection, once satisfactory lung expansion was verified, two 28- or 32-Fr intercostal drains were placed in the pleural space, one at the apex and one on the diaphragm, respectively, working as outflow and inflow drainage during the perfusion. A temperature probe was also placed into the pleural cavity, and the thoracotomy was eventually closed (Video 1). Operative time was defined as the time between skin incision and the end of the perfusion. All patients were extubated at the end of the procedure.

\section{Devices and Perfusion Technique}

Perfusion was run with patients in lateral decubitus and the lung was not ventilated. In all procedures, a dedicated perfusion system, Performer LRT (Rand, Medolla, MO, Italy), with software for locoregional hyperthermic oncological treatments, was used to perform HITHOC. The volume of perfusion, preloaded in the machine, was calculated in liters, based on the value of the body surface and then doubled to keep the same proportion of chemotherapy agents among all patients. After the connection of the device to inflow and outflow drainages, pleural space was gradually filled with the preloaded isotonic saline solution at a temperature of $38^{\circ} \mathrm{C}$; careful attention was paid to fill the entire pleural space until no air was coming out from the tubes. The temperature was then progressively increased to obtain an intrathoracic target temperature of $42.5^{\circ} \mathrm{C}$; once the target temperature was reached, chemotherapeutic agents were added into the system and perfusion was then continued for 60 minutes. We use 2 chemotherapeutic drugs: cisplatin (dose, $\left.80 \mathrm{mg} / \mathrm{m}^{2}\right)$ and epirubicin $\left(25 \mathrm{mg} / \mathrm{m}^{2}\right)$. Blood pressure, cardiac frequency, oxygen saturation, and core and chest cavity temperatures were continuously monitored and recorded the entire perfusion time. At the end of the perfusion, inflow and outflow drains were exchanged to empty the pleural space, temperature probes were removed, and the lung was ventilated again.

\section{Postoperative Management}

Broad-spectrum antibiotic therapy was administered until removal of the chest drain and low-molecular-weight heparin administration was continued until discharge. Blood count, liver and renal function tests, and D-dimer blood levels were monitored daily for the first 5 postoperative days. Morbidity, 30-day, and 90-day mortality and postoperative stay were recorded. Any adverse event was stratified with the Common Terminology Criteria for Adverse Events, version 4.03.

\section{Diaphragm and Pericardium preserving Pleurectomy and partial Decortication with HITHOC for treatment of Malignant Pleural Mesothelioma: a 10 year experience Marcello Carlo Ambrogi PhD, Pietro Bertoglio MD, Antonio Chella MD, Stylianos Korasidis MD,
Gabriella Fontanini PhD, Gabriele Massimetti, Vittorio Aprile MD, Marco Lucchi MD, Alfredo Mussi MD \\ University Hospital of Pisa, Italy}

VIDEO 1. The main steps of our surgical technique of pleurectomy and focal decortication followed by hyperthermic intrathoracic chemotherapy are shown. Video available at: http://www.jtcvsonline.org/article/S00225223(17)32399-1/fulltext.

\section{Adjuvant Treatments and Follow-up}

The final pathology report was first discussed by a multidisciplinary team and then with the patient. At least 3 cycles of adjuvant chemotherapy (cisplatin $80 \mathrm{mg} / \mathrm{m}^{2}$ and pemetrexed $500 \mathrm{mg} / \mathrm{m}^{2}$ ) were scheduled for all patients, and follow-up was carried out with chest and abdominal CT every 6 months; prophylactic radiotherapy and further systemic or local treatments were administered according to the choice of the referring oncologists. Follow-up information (vital status, adverse events after discharge, and their severity and presence of any recurrence) was gathered by the authors from the referring oncologist and by a direct call to the patients or to their relatives.

\section{Statistical Analysis}

Statistical analysis was performed with SPSS software version 18.0 for Windows (SPSS, Chicago, Ill). Continuous variables were expressed in terms of median and interquartile range, whereas categorical variables were expressed in terms of frequency.

Overall survival (OS) was estimated with Kaplan-Meier estimator with a $95 \%$ confidence interval (CI). Survival was calculated from the date of surgery to last follow-up (December 2015) or death. Disease-free interval (DFI) was based on the cumulative incidence estimate with death considered as a competing risk, and it was calculated from the date of surgery to the first evidence of recurrence. Mortality after documented recurrence or progression was considered to be disease-related unless a clear different cause was proved.

Survival comparison between groups of patients undergoing surgical resection with HITHOC was performed with the log-rank test for categorical variables and Cox regression for continuous variables. Considering the recent results emphasizing the role of inflammation on the onset of MPM, ${ }^{14}$ we decided to analyze the impact of inflammatory markers on OS. Preoperative fibrinogen and albumin levels were calculated as continuous variables, whereas platelet/lymphocyte ratio (PLR) and neutrophil/ lymphocyte ratio (NLR) cutoffs were chosen on the basis of past published experiences (200 and 4, respectively). ${ }^{15,16}$ Multivariable analysis with the Cox proportional hazards model was applied to identify predictors for OS. Prognostic factors that were significant at the univariate analysis were used to perform a multivariate analysis. A $P$ value $<.05$ was considered statistically significant.

\section{RESULTS}

This study included 49 patients ( 41 male, 8 female), with a median age of 68 years (range 35-76). Histologic diagnosis was obtained by a thoracoscopic procedure performed at our division in all but 2 cases. The median interval between the thoracoscopic procedure and the P/D plus HITHOC procedure was 33 days (range, 7-90 days). Before surgery, no patients presented with known cardiovascular diseases or hepatic or renal function alterations. Demographic, clinical, and surgical features are summarized in Table 1.

The surgical procedure consisted of pleurectomy and partial decortication, and in 4 cases a wedge resection of the lung was necessary. The pericardium and diaphragm were always spared. The median operative time, including preparation of the perfusion circuit and perfusion time, was 240 minutes (range, 160-315).

\section{Pathology}

The seventh edition of International Mesothelioma Interest Group mesothelioma classification was used to stage the 
TABLE 1. Demographic, clinical, and surgical features of all patients

\begin{tabular}{|c|c|}
\hline Features & n $(\%)$ or IQR \\
\hline \multicolumn{2}{|l|}{ Sex } \\
\hline Male & $41(83.7)$ \\
\hline Female & $8(16.3)$ \\
\hline Median age, y (IQR) & $68(11)$ \\
\hline \multicolumn{2}{|l|}{ Side } \\
\hline Right & $29(50.2)$ \\
\hline Left & $20(49.8)$ \\
\hline Median body mass index (IQR) & $25.9(4.4)$ \\
\hline \multicolumn{2}{|l|}{ Median preoperative pulmonary function test (IQR) } \\
\hline FEV1, L & $2.20(1.3)$ \\
\hline FEV1, \% & $56(16)$ \\
\hline FVC, L & $2.4(0.9)$ \\
\hline $\mathrm{FVC}, \%$ & $58(17)$ \\
\hline Comorbidities & $40(82)$ \\
\hline Diabetes & $12(24.5)$ \\
\hline Hypertension & $31(63.3)$ \\
\hline Pulmonary disease (COPD or asthma) & $25(51.02)$ \\
\hline Other cardiovascular disease & $3(6.12)$ \\
\hline Previous cancer & $7(14.3)$ \\
\hline \multicolumn{2}{|l|}{ ECOG } \\
\hline 0 & $32(65.3)$ \\
\hline 1 & $17(34.7)$ \\
\hline \multicolumn{2}{|l|}{ Histology } \\
\hline Epithelioid & $43(87.8)$ \\
\hline Biphasic & $6(12.2)$ \\
\hline \multicolumn{2}{|l|}{ Smoking } \\
\hline Smoker/ex-smoker & $16(32.7)$ \\
\hline Nonsmoker & $24(49.0)$ \\
\hline Missing data & $9(18.4)$ \\
\hline \multicolumn{2}{|l|}{ Asbestos exposure } \\
\hline Positive & $23(46.9)$ \\
\hline Negative & $7(14.3)$ \\
\hline Uncertain/missing data & $19(38.8)$ \\
\hline Median number of lymph node resected (IQR) & $11(3.6)$ \\
\hline Median number of N2 lymph node station resected (IQR) & $3(1)$ \\
\hline \multicolumn{2}{|l|}{ pT } \\
\hline T1a & $4(8.2)$ \\
\hline $\mathrm{T} 1 \mathrm{~b}$ & $8(16.3)$ \\
\hline $\mathrm{T} 2$ & $18(36.7)$ \\
\hline $\mathrm{T} 3$ & $16(32.7)$ \\
\hline $\mathrm{T} 4$ & $3(6.1)$ \\
\hline \multicolumn{2}{|l|}{$\mathrm{pN}$} \\
\hline No & $39(79.6)$ \\
\hline $\mathrm{N} 1$ & $0(0.0)$ \\
\hline N2 & $10(20.4)$ \\
\hline \multicolumn{2}{|l|}{ Pathologic IMIG stage } \\
\hline IA & $4(8.2)$ \\
\hline IB & $8(16.3)$ \\
\hline II & $14(28.6)$ \\
\hline III & $20(40.8)$ \\
\hline IV & $3(6.1)$ \\
\hline
\end{tabular}

$I Q R$, Interquartile range; $F E V l$, forced expiratory volume in 1 second; $F V C$, forced vital capacity; $C O P D$, chronic obstructive pulmonary disease; $E C O G$, Eastern Cooperative Oncology Group performance status; IMIG, International Mesothelioma Interest Group. disease. ${ }^{17}$ Histology was epithelioid in 43 cases and biphasic in 6 cases. Pathologic stage I, II, III, and IV was presented in 12 (4 stage IA and 8 stage IB), 14, 20, and 3 cases, respectively. All stages IV were due to a T4 tumor that unexpectedly involved the chest wall.

\section{Morbidity and Mortality}

No intraoperative complications occurred, and HITHOC perfusion was successfully completed in all cases; in one case perfusion was stopped after 45 minutes due to technical problems. Median hospital stay was 8 days (range, 5-45). No thermal intolerance and no anesthesiologic complications occurred during the perfusion period. The core temperature never exceeded $38^{\circ} \mathrm{C}$. Moreover, neither hemodynamic nor respiratory instability was observed. No patient experienced signs or symptoms related to the toxicity of the chemotherapy used. Reversal of anesthesia was always performed at the end of the procedure, and no patient needed to be hospitalized in the intensive care unit.

Postoperative complications appeared in 23 patients (46.9\%; 95\% CI, 30-59) (Table 2); the most common cause of morbidity was anemia, which occurred in 17 cases $(34.7 \%)$, of whom 13 required a blood transfusion with a median number of red cell unit used of 2.5 (range, 1-11); 1 of those patients required reoperation to check hemostasis. Only 4 patients were affected by prolonged airleaking (more than 5 days, $8.1 \%$ ); only one case of postoperative empyema was observed, which finally resolved with chest drain and antibiotic therapy. All postoperative complications are summarized in Table 2.

TABLE 2. Description of all postoperative complications

\begin{tabular}{lcc}
\hline \multicolumn{1}{c}{ Type of complication(s) } & CTCAE 4.03 & Number of patients \\
\hline Prolonged air leak* & 3 & 2 \\
\hline $\begin{array}{l}\text { Anemia without need for } \\
\text { transfusion }\end{array}$ & 2 & 4 \\
$\begin{array}{l}\text { Anemia with need for } \\
\text { transfusion }\end{array}$ & 3 & $\begin{array}{c}\text { Nine, of whom 1 required a } \\
\text { surgical hemostasis }\end{array}$ \\
\hline $\begin{array}{l}\text { Wound dehiscence } \dagger \\
\text { Fever (>38.5 C for at least } \\
24 \text { h) }\end{array}$ & 1 & 2 \\
\hline $\begin{array}{l}\text { Syncope } \\
\text { Ischemic cerebral vascular } \\
\text { accident and anemia with } \\
\text { need for transfusion }\end{array}$ & 2 & 1 \\
\hline $\begin{array}{l}\text { Anemia with need for } \\
\text { transfusion and prolonged } \\
\text { air leak }\end{array}$ & 3 & 1 \\
\hline $\begin{array}{l}\text { Anemia with need for } \\
\text { transfusion, wound } \\
\text { dehiscence and empyema } \dagger\end{array}$ & 3 & 2 \\
\hline
\end{tabular}

CTCAE, Common Terminology Criteria for Adverse Events version 4.03. * Longer than 5 days. $\dagger$ Diastases of the ribs during the postoperative follow-up control, which was not visible on postoperative radiographs. 
All patients successfully completed the first 3 cycles of adjuvant therapy with cisplatin and pemetrexed. The administration of the adjuvant radiotherapy was decided by the referring oncologist according to the $\mathrm{N}$ status, pathologic stage, and patient clinical conditions; among the whole cohort, 3 patients received a 60-Gy adjuvant radiotherapy. Grade 2 and grade 3 toxicity occurred in one case each, but all patients were able complete their planned adjuvant radiation.

\section{Oncologic Outcomes}

At a median follow-up of 68.5 months (range, 13-127), 14 patients were still alive. We had no cases of mortality in the first 90 postoperative days $(95 \%$ CI, 0-7.2). Median OS of the entire cohort was 22 months with 30 and 90 days and 1-, 2-, and 5- year survival of $100 \%, 100 \%$ $79.6 \%, 45.7 \%$, and $9.9 \%$, respectively (Figure 1); 27 patients died after a recurrence of the disease; in 3 cases death was due to chemotherapy toxicity (treatments administered for recurrence), and 5 patients died due to causes not related to the disease or treatments. Concurrently, DFI was $62 \%$, $37.5 \%$, and $18.5 \%$ at 1,2 , and 5 years, respectively, and recurrence occurred in 39 patients $(79.6 \%)$; precise information about the site of recurrence was missing in 4 cases. Recurrences were mainly local (ipsilateral chest wall, diaphragm or pericardium, drain wounds), accounting for 23 cases, whereas in 4 cases the recurrence was exclusively distant (mediastinal nodes or any other systemic localization) and in 8 cases was both local and distant.

\section{Prognostic Factors}

On the log-rank analysis (Table 3), age older 65 years, sex, side, Eastern Cooperative Oncology Group score, and postoperative complications were not significant factors influencing OS. Conversely, the histology resulted a very strong prognostic factor where epithelioid MPM had a significant better prognosis rather than biphasic $(P=.022)$;

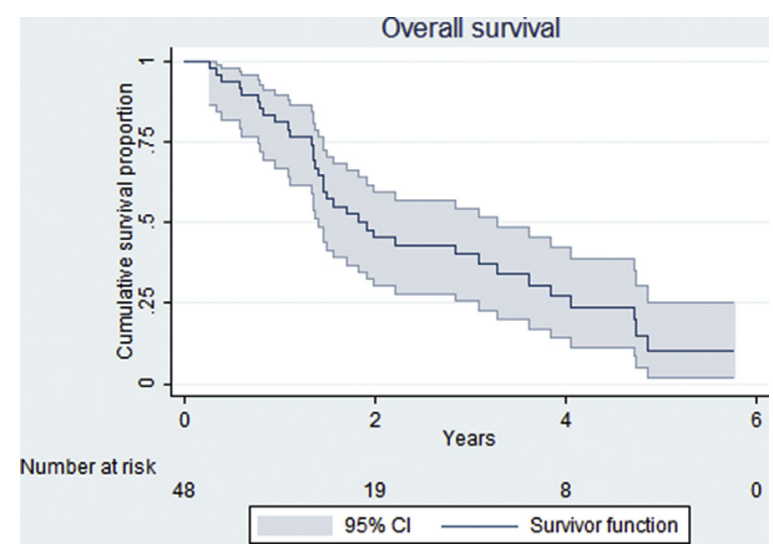

FIGURE 1. Overall survival of the entire cohort of patients. CI, Confidence interval. moreover, early stage (I and II) MPM had a median OS of 35 months, significantly better compared with advanced stages (III and IV, 17 months; $P=.049$ ). With regard to the univariate analysis of inflammatory markers, preoperative fibrinogen level, PLR, and NLR resulted significant risk factors affecting OS and showed a significant impact on OS. in the univariate analysis.

Multivariate analysis (Table 4) showed that the epithelioid histology, early stages, and low fibrinogen serum levels were associated with a better prognosis (hazard ratio [HR], 0.341; 95\% CI, 0.120-0.968, $P=.043$; HR, 0.303; 95\% CI, 0.123-0.749, $P=.010$; and HR, 1.007 ; $95 \% \mathrm{CI}$, 1.004-1.011, $P<.001$, respectively).

\section{DISCUSSION}

The role of surgery in mesothelioma treatment has not yet been fully established. EPP, EPD, and P/D are currently the surgical approaches that are most frequently proposed, but indications and outcomes of these approaches are inconsistent, varying according to different experiences. ${ }^{18,19}$ Lung preservation seems to be a fundamental factor to increase both patients' indication to surgery and their compliance to a multimodality treatment. ${ }^{20}$ In our experience, both lung and diaphragm were spared in all cases, and all patients successfully completely the planned multimodality treatment.

MCR is usually considered the goal of mesothelioma surgery, ${ }^{6}$ even if a real $\mathrm{R} 0$ resection is not anatomically possible according to the common oncologic parameters, as the anatomical features of the pleura do not allow one to reach a disease-free margin regardless of the type of procedure performed. ${ }^{21} \mathrm{R} 1$ resection is considered the gold standard for mesothelioma surgery, which is usually performed in the frame of a multidisciplinary scheme of therapies. Sharkey and colleagues ${ }^{22}$ recently reported the experience of their group in the management of diaphragm after radical surgery for mesothelioma (both EPP and EPD). They observed that diaphragm invasion was not an independent prognostic factor, although their conclusions are that, in case of doubt, diaphragm resection should be performed to stay on the safe side, and their data question the necessity of a routine phrenectomy. In our study, we reported our 10-year experience in mesothelioma surgery; our aim was to look at mesothelioma surgery from a different perspective: our main target was to perform a MCR or to leave a small quantity of disease (minimal R2) but always preserve pulmonary and diaphragmatic function. HITHOC was applied with the aim to extend the radicality of our surgical resection by the local effect of chemotherapy agents on residual tumor. This choice of action aimed to guarantee a plausible better performance status after surgery, allowing the patients to undergo adjuvant therapies or different treatments for recurrences.

Cisplatin has been demonstrated to be an effective drug for mesothelioma, and several papers report its use it in 
TABLE 3. Univariate analysis of risk factors influencing $\mathrm{OS}$

\begin{tabular}{|c|c|c|c|c|}
\hline Risk factor & Median OS (months) & $\begin{array}{c}\text { Lower } \\
\text { CI }\end{array}$ & $\begin{array}{l}\text { Upper } \\
\text { CI }\end{array}$ & $\begin{array}{r}\text { Log-rank } \\
(P \text { value })\end{array}$ \\
\hline Age, y & & & & .804 \\
\hline$<65$ & 23 & 1.92 & 44.08 & \\
\hline$\geq 65$ & 18 & 9.88 & 26.11 & \\
\hline Age (continuous variable) & NA & 0.97 & 1.06 & .501 \\
\hline Sex & & & & .991 \\
\hline Male & 22 & 16.12 & 27.87 & \\
\hline Female & 43 & 0 & 93.53 & \\
\hline Side & & & & .799 \\
\hline Right & 20 & 2.96 & 37.04 & \\
\hline Left & 22 & 15.86 & 28.13 & \\
\hline ECOG & & & & .563 \\
\hline 0 & 22 & 17.05 & 26.95 & \\
\hline$\geq 1$ & 18 & 5.16 & 30.83 & \\
\hline FEV1 (continuous variable) & NA & 0.02 & 2.04 & .106 \\
\hline Postoperative complications & & & & .402 \\
\hline Yes & 26 & 11.41 & 40.59 & \\
\hline No & 17 & 14.27 & 19.73 & \\
\hline Histology & & & & .022 \\
\hline Epithelioid & 23 & 5.21 & 40.77 & \\
\hline Biphasic & 10 & 0.39 & 19.60 & \\
\hline IMIG stage & & & & .049 \\
\hline Early (I-II) & 35 & 16.53 & 53.57 & \\
\hline Late (III-IV) & 17 & 14.17 & 19.83 & \\
\hline Fibrinogen, mg/dL (continuous variable) & NA & 1.004 & 1.009 & $<.001$ \\
\hline Albumin, g/dL (continuous variable) & NA & 0.22 & 1.28 & .151 \\
\hline PLR & & & & .001 \\
\hline$<200$ & 36 & 13.46 & 58.54 & \\
\hline$\geq 200$ & 17 & 13.68 & 20.32 & \\
\hline NLR & & & & .030 \\
\hline$<4$ & 23 & 4.77 & 41.23 & \\
\hline$\geq 4$ & 18 & 13.58 & 22.42 & \\
\hline
\end{tabular}

Analysis was calculated with log-rank test for categorical variables and Cox regression for continuous variables. Significance was considered for $P<.05,95 \%$ CI. $P$ values in bold indicate statistical significance. Fibrinogen, albumin, NLR, and PLR refer to preoperative serum levels. $O S$, Overall survival; $C I$, confidence interval; $N A$, not available; $E C O G$, Eastern Cooperative Oncology Group; FEVI, forced expiratory volume in 1 second; $I M I G$, International Mesothelioma Interest Group; $P L R$, platelet/lymphocyte ratio; NLR, neutrophil/lymphocyte ratio.

an intrapleural setting. Sugarbaker ${ }^{12}$ recently reported a retrospective study comparing the oncologic outcomes of patients affected by MPM with good prognostic factors treated with EPP or P/D with and without the use of
HITHOC after surgery; results showed a better median OS for patients receiving HITHOC surgery (35.3 months vs 22.8 months) and, in particular, better outcomes were observed with HITHOC for patients with a nodal

TABLE 4. Multivariate analysis of risk factors influencing overall survival

\begin{tabular}{|c|c|c|c|c|}
\hline & \multirow[b]{2}{*}{ Hazard ratio } & \multicolumn{2}{|c|}{$95 \% \mathrm{CI}$} & \multirow[b]{2}{*}{$P$ value } \\
\hline & & Inferior & Superior & \\
\hline Epithelioid histology & 0.341 & 0.120 & 0.968 & .043 \\
\hline Early stage (I and II) & 0.303 & 0.123 & 0.749 & .010 \\
\hline Fibrinogen (continuous variable) & 1.007 & 1.004 & 1.011 & $<.001$ \\
\hline PLR $<200$ & 0.523 & 0.164 & 1.668 & .273 \\
\hline NLR $<4$ & 0.944 & 0.358 & 2.488 & .907 \\
\hline
\end{tabular}

Analysis was calculated with Cox regression models. Significance was considered for $P<.05$ for a CI between $5 \%$ and $95 \% . P$ values in bold indicate statistical significance. Fibrinogen, albumin, NLR, and PLR refer to preoperative serum levels. $C I$, Confidence interval; PLR, platelet/lymphocyte ratio; $N L R$, neutrophil/lymphocyte ratio. 
TABLE 5. Results of studies using surgery for malignant pleural mesothelioma

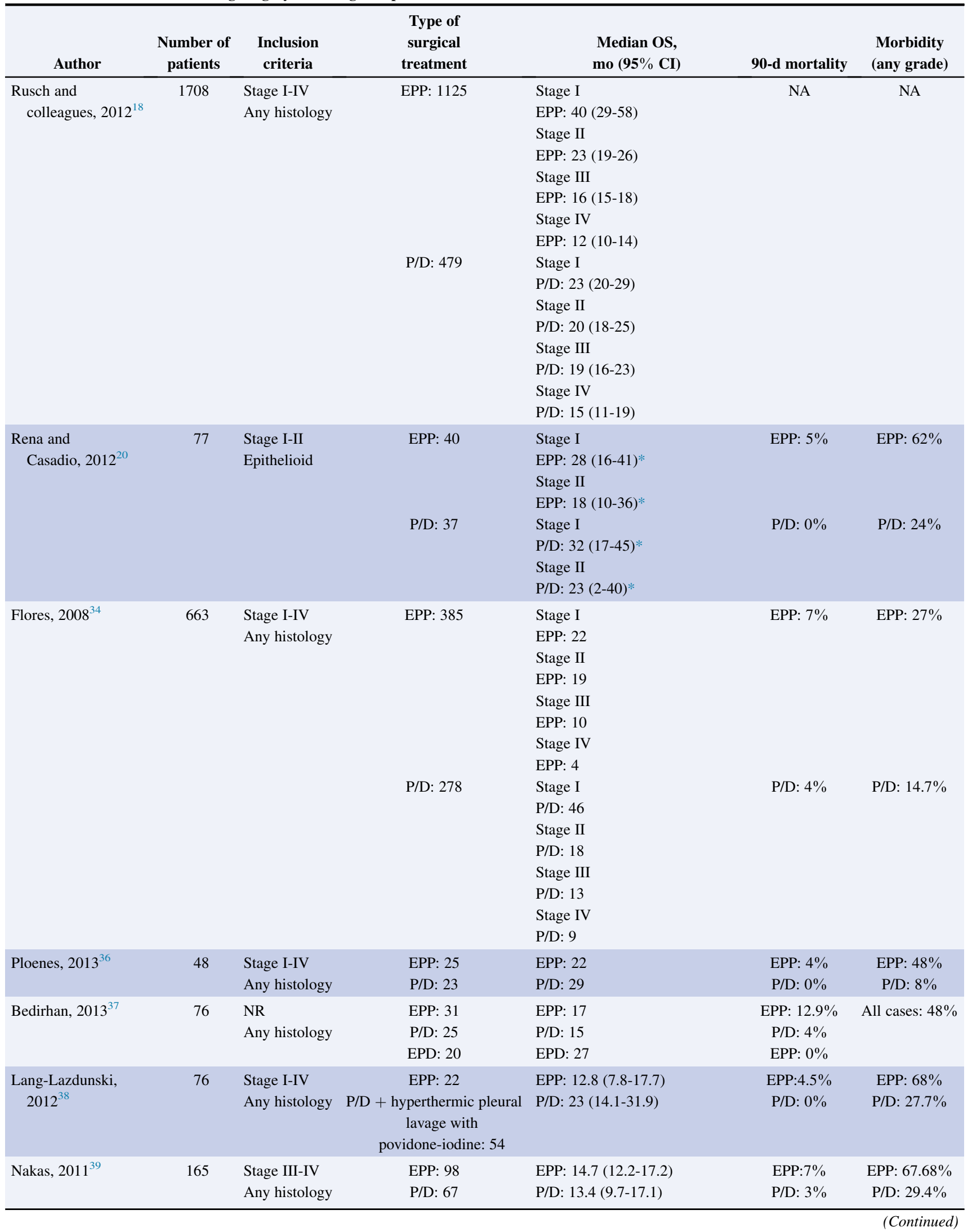


TABLE 5. Continued

\begin{tabular}{lclccc}
\hline \multicolumn{1}{c}{ Author } & $\begin{array}{c}\text { Number of } \\
\text { patients }\end{array}$ & $\begin{array}{c}\text { Inclusion } \\
\text { criteria }\end{array}$ & $\begin{array}{c}\text { Type of } \\
\text { surgical } \\
\text { treatment }\end{array}$ & $\begin{array}{c}\text { Median OS, } \\
\text { mo (95\% CI) }\end{array}$ & $\begin{array}{c}\text { Morbidity } \\
\text { 90-d mortality }\end{array}$ \\
\hline (any grade)
\end{tabular}

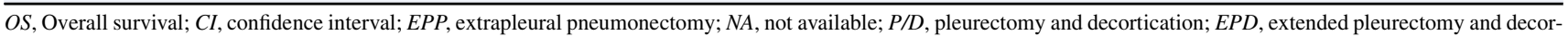
tication; HITHOC, hyperthermic intrathoracic intraoperative chemotherapy. *Range.

involvement. A more recent report of Ishibashi and coworkers ${ }^{23}$ compared the DFI after EPP or P/D both associated with HITHOC with cisplatin; despite the very small cohort of patients with significant differences in pathologic stage, they noticed a significant better DFI after P/D.

The pharmacokinetics of HITHOC using cisplatin alone or in association with anthracyclines have been investigated by several authors, ${ }^{9,24-27}$ confirming its feasibility and its low systemic exposure; doxorubicin has shown to have a quite low penetration factor into the tissues compared with cisplatin; moreover, direct cardiac toxicity of doxorubicin has been discussed, but no clear evidence is available and results are inconsistent. Concurrently, the dosage of drugs used for HITHOC is very variable based on single-institution protocols; dosages of cisplatin have been reported to be up to $225 \mathrm{mg} / \mathrm{m}^{2}$ when used alone, and doxorubicin is usually administered at a dose of $80 \mathrm{mg} / \mathrm{m}^{2} .{ }^{10}$ Hyperthermia seems to play a key role in the local control of the disease, enabling drugs to penetrate more deeply into the tissue and to enhance their cytotoxic effects. Schaaf and colleagues ${ }^{28}$ recently studied the in vitro effects of temperature during hyperthermic intraperitoneal chemotherapy, confirming that $40^{\circ} \mathrm{C}$ is the ideal threshold to obtain a benefit in terms of OS and DFI; Ratto and colleagues ${ }^{9}$ and Matsuzaki and colleagues ${ }^{29}$ confirmed the adjuvant effect of hyperthermia; nevertheless, a recent in vitro study ${ }^{30}$ questioned its role, stressing the importance of the use of a combination of drugs.

In our study, the same combination of drugs and dosage (cisplatin $80 \mathrm{mg} / \mathrm{m}^{2}$ and epirubicin $25 \mathrm{mg} / \mathrm{m}^{2}$ ) was administrated to all patients with perfusion at a target temperature of $42.5^{\circ} \mathrm{C}$ for 60 minutes, according to our protocol. To date, no case of systemic toxicity due to drugs has been experienced.

Postoperative mortality and morbidity are serious drawbacks of EPP and EPD. In fact, these operations are burdened with a relatively high mortality: a recent meta-analysis found a mortality rate ranging from $3.7 \%$ to $7.6 \%$ for $\mathrm{EPP}^{31}$ and $4 \%$ for $\mathrm{EPD}$ or $\mathrm{P} / \mathrm{D}^{32}$; moreover, the major complication rate was almost $50 \%$ in EPP and up to $43 \%$ in EPD-P/D. ${ }^{33}$ In our experience, no case of mortality was observed in the first 90 days from surgery, and our complication rate was $46.9 \%$, comparable with other experiences. In particular, among the 22 patients who experienced complications, only 14 had a severe complication (classified as stage 3 according to Common Terminology Criteria for Adverse Events, version 4.03; no stage 4 complications were registered). It is clear that MPM cannot be considered a purely surgical disease; in fact, surgery cannot achieve a R0 resection in any case, due to anatomical features, and it is always part of a multimodality treatment ${ }^{3}$; moreover, patients are very likely to need treatments for recurrence. From this perspective, any surgical procedure should offer an extensive resection of the tumor, attempting to preserve performance status and respiratory function, offering a low postoperative complication profile. It is hard to quantify the impact of a diaphragm and pericardium resection on postoperative morbidity and mortality, but retrospective series has shown that invasive procedures such as EPP do not have any survival benefit compared with $\mathrm{P} / \mathrm{D}$, that they have a high mortality rate, and that one third of patients are generally unable to complete the multimodality treatment. Moreover, extended resections have a clear selection bias because only patients with an acceptable preoperative performance status are able to undergo these procedures. Lastly, in some reports no difference in terms of OS has been found between patients treated with multimodality treatment including EPP or EPD and those who received only systemic treatments. ${ }^{7,8,34}$ Our approach seems to fit all these criteria, and in our small cohort of patients, oncologic results seem to be at least comparable with those which were previously reported (Table 5).

Consistent with the literature, ${ }^{3}$ local recurrence was the main pattern of failure that we noticed in our experience. The treatment of recurrence was generally decided by the referring oncologist after multidisciplinary discussion; 
systemic therapy or immunotherapy was the treatment of choice as well as radiotherapy.

In 1 case, we performed a chest wall resection for recurrence. Abdominal recurrences are one main pattern of failure after resection of the diaphragm. ${ }^{35}$ Consistent with the literature, in our cohort, only 1 case was reported to have an intra-abdominal recurrence, whereas in 4 cases the diaphragm was the site of recurrence. Not surprisingly, these data might confirm that diaphragm resection can cause a neoplastic seeding of the peritoneum, which might be prevented if the diaphragm is preserved.

In the analysis of prognostic factors, we confirmed the role of inflammatory markers; high fibrinogen levels were first described as an important prognostic factor for MPM by Ghanim and colleagues, ${ }^{14}$ and we observed a strict relationship with OS also in our cohort. This strict relationship has been proven for several malignancies and it might be explained either as a result of the immune response against the tumor or to the increased autocrine growth stimulation. NLR and PLR showed to have a good prognostic value in literature, but this was not confirmed in our report. Nonetheless, the impact of all these prognostic factors on the choice of the therapy is still very limited, and further perspective, randomized trials are needed to assess their use in daily clinical practice.

Our study has some limitations. First, it is a retrospective study, and the relatively small cohort of patients as well as the selection criteria might limit the strength of our conclusions; second, there was no objective postoperative assessment of quality of life and pulmonary function. This would have been useful to investigate the long-term outcomes after our procedure; moreover, a clear definition of $\mathrm{R} 1$ or minimal $\mathrm{R} 2$ resection was not always available in the operative reports, and it was therefore impossible to define it clearly. Finally, our protocol included 3 cycles of adjuvant chemotherapy with cisplatin and pemetrexed, but any further therapies or treatments in case of recurrence were then decided according to the referring oncologist's preference. In conclusion, pleurectomy and focal decortication with a systematic sparing of the diaphragm and pericardium associated with HITHOC is a feasible and safe procedure leading to satisfactory long-term results. Although larger, controlled studies are needed to confirm our promising outcomes, this experience confirms that the preservation of lung and diaphragm, and a low postoperative rate of high-grade morbidity or mortality might be a more important argument than a macroscopic radicality for oncologic results after surgery.

\section{Conflict of Interest Statement}

Authors have nothing to disclose with regard to commercial support.

The authors thank Mr Matteo Valerio, Professor Gabriele Massimetti, and Mrs Theresa Hung Key for their valued help in editing the manuscript.

\section{References}

1. Hodgson JT, McElvenny DM, Darnton AJ, Price MJ, Peto J. The expected burden of mesothelioma mortality in Great Britain from 2002 to 2050. Br J Cancer. 2005;92:587-93

2. Vogelzang NJ, Rusthoven JJ, Symanowski J, Denham C, Kaukel E, Ruffie P, et al. Phase III study of pemetrexed in combination with cisplatin versus cisplatin alone in patients with malignant pleural mesothelioma. J Clin Oncol. 2003;21: 2636-44.

3. Bertoglio P, Waller DA. The role of thoracic surgery in the management of mesothelioma: an expert opinion on the limited evidence. Expert Rev Respir Med. 2016;10:663-72.

4. Wolf AS, Flores RM. Current treatment of mesothelioma: extrapleural pneumonectomy versus pleurectomy/decortication. Thorac Surg Clin. 2016;26: 359-75.

5. Rice D, Rusch V, Pass H, Asamura H, Nakano T, Edwards J, et al. Recommendations for uniform definitions of surgical techniques for malignant pleural mesothelioma: a consensus report of the international association for the study of Lung Cancer International Staging Committee and the International Mesothelioma Interest Group. J Thorac Oncol. 2011;6:1304-12.

6. Sugarbaker DJ. Macroscopic complete resection: the goal of primary surgery in multimodality therapy for pleural mesothelioma. J Thorac Oncol. 2006;1: 175-6.

7. Bovolato P, Casadio C, Billè A, Ardissone F, Santambrogio L, Ratto GB, et al. Does surgery improve survival of patients with malignant pleural mesothelioma? A multicenter retrospective analysis of 1365 consecutive patients. J Thorac Oncol. 2014;9:390-6.

8. Rena O, Boldorini R, Papalia E, Mezzapelle R, Baietto G, Roncon A, et al. Persistent lung expansion after pleural talc poudrage in non-surgically resected malignant pleural mesothelioma. Ann Thorac Surg. 2015;99:1177-83.

9. Ratto GB, Civalleri D, Esposito M, Spessa E, Alloisio A, De Cian F, et al. Pleural space perfusion with cisplatin in the multimodality treatment of malignant mesothelioma: a feasibility and pharmacokinetic study. J Thorac Cardiovasc Surg. 1999; 117:759-65.

10. Gomez D, Tsao AS. Local and systemic therapies for malignant pleural mesothelioma. Curr Treat Options Oncol. 2014;15:683-99.

11. Tilleman TR, Richards WG, Zellos L, Johnson BE, Jaklitsch MT, Mueller J, et al Extrapleural pneumonectomy followed by intracavitary intraoperative hyperthermic cisplatin with pharmacologic cytoprotection for treatment of malignant pleural mesothelioma: a phase II prospective study. J Thorac Cardiovasc Surg. 2009; 138:405-11.

12. Sugarbaker DJ, Gill RR, Yeap BY, Wolf AS, DaSilva MC, Baldini EH, et al. Hy perthermic intraoperative pleural cisplatin chemotherapy extends interval to recurrence and survival among low-risk patients with malignant pleural mesothelioma undergoing surgical macroscopic complete resection. J Thorac Cardiovasc Surg. 2013;145:955-63.

13. Bertoglio P, Ambrogi A, Chella A, Aprile V, Dini P, Korasidis S, et al. Is less also better? A single-institution experience on treatment of early stage malignant pleural mesothelioma. Eur J Surg Oncol. 2017;43:1365-71.

14. Ghanim B, Hoda MA, Klikovits T, Winter MP, Alimohammadi A, Grusch M et al. Circulating fibrinogen is a prognostic and predictive biomarker in malignant pleural mesothelioma. Br J Cancer. 2014;110:984-90.

15. Cihan YB, Ozturk A, Mutlu H. Relationship between prognosis and neutrophil: lymphocyte and platelet:lymphocyte ratios in patients with malignant pleural mesotheliomas. Asian Pac J Cancer Prev. 2014;15:2061-7.

16. Pinato DJ, Mauri FA, Ramakrishnan R, Wahab L, Lloyd T, Sharma R. Inflammation-based prognostic indices in malignant pleural mesothelioma. J Thorac Oncol. 2012;7:587-94.

17. American Joint Committee on Cancer. AJCC Cancer Staging Manual. 7th ed New York: Springer; 2010.

18. Rusch VW, Giroux D, Kennedy C, Ruffini E, Cangir AK, Rice D, et al. Initial analysis of the international association for the study of lung cancer mesothelioma database. J Thorac Oncol. 2012;7:1631-9.

19. Treasure T, Lang-Lazdunski L, Waller D, Bliss JM, Tan C, Entwisle J, et al. Extra-pleural pneumonectomy versus no extra-pleural pneumonectomy for patients with malignant pleural mesothelioma: clinical outcomes of the Mesothelioma and Radical Surgery (MARS) randomised feasibility study. Lancet Oncol. 2011;12:763-72.

20. Rena O, Casadio C. Extrapleural pneumonectomy for early stage malignant pleural mesothelioma: a harmful procedure. Lung Cancer. 2012;77:151-5.

21. Flores RM. Pleurectomy decortication for mesothelioma: the procedure of choice when possible. J Thorac Cardiovasc Surg. 2016;151:310-2. 
22. Sharkey AJ, Bilancia R, Tenconi S, Nakas A, Waller DA. The management of the diaphragm during radical surgery for malignant pleural mesothelioma. Eur J Cardiothorac Surg. 2016;50:311-6.

23. Ishibashi $\mathrm{H}$, Kobayashi M, Takasaki C, Okubo K. Interim results of pleurectomy/ decortication and intraoperative intrapleural hyperthermic cisplatin perfusion for patients with malignant pleural mesothelioma intolerable to extrapleural pneumonectomy. Gen Thorac Cardiovasc Surg. 2015;63:395-400.

24. van Ruth S, van Tellingen O, Korse CM, Verwaal VJ, Zoetmulder FA. Pharmacokinetics of doxorubicin and cisplatin used in intraoperative hyperthermic intrathoracic chemotherapy after cytoreductive surgery for malignant pleural mesothelioma and pleural thymoma. Anticancer Drugs. 2003;14:57-65.

25. Bogliolo GV, Lerza R, Bottino GB, Mencoboni MP, Pannacciulli IM, Vannozzi M, et al. Regional pharmacokinetic selectivity of intrapleural cisplatin. Eur J Cancer. 1991;27:839-42.

26. de Bree E, van Ruth S, Schotborgh CE, Baas P, Zoetmulder FA. Limited cardiotoxicity after extensive thoracic surgery and intraoperative hyperthermic intrathoracic chemotherapy with doxorubicin and cisplatin. Ann Surg Oncol. 2007; 14:3019-26.

27. Ried M, Lehle K, Neu R, Diez C, Bednarski P, Sziklavari Z, et al. Assessment of cisplatin concentration and depth of penetration in human lung tissue after hyperthermic exposure. Eur J Cardiothorac Surg. 2015;47:563-6.

28. Schaaf L, van der Kuip H, Zopf W, Winter S, Münch M, Mürdter TE, et al. A temperature of $40^{\circ} \mathrm{C}$ appears to be a critical threshold for potentiating cytotoxic chemotherapy in vitro and in peritoneal carcinomatosis patients undergoing HIPEC. Ann Surg Oncol. 2015;22(suppl 3):S758-765.

29. Matsuzaki Y, Tomita M, Shimizu T, Hara M, Ayabe T, Onitsuka T. Induction of apoptosis by intrapleural perfusion hyperthermo-chemotherapy for malignant pleural mesothelioma. Ann Thorac Cardiovasc Surg. 2008;14: $161-5$.

30. Cameron RB, Hou D. Intraoperative hyperthermic chemotherapy perfusion for malignant pleural mesothelioma: an in vitro evaluation. J Thorac Cardiovasc Surg. 2013;145:496-504.

31. Cao CQ, Yan TD, Bannon PG, McCaughan BC. A systematic review of extrapleural pneumonectomy for malignant pleural mesothelioma. J Thorac Oncol. 2010;5:1692-703.

32. Teh E, Fiorentino F, Tan C, Treasure T. A systematic review of lung-sparing extirpative surgery for pleural mesothelioma. J R Soc Med. 2011;104:69-80.
33. Cao C, Tian DH, Pataky KA, Yan TD. Systematic review of pleurectomy in the treatment of malignant pleural mesothelioma. Lung Cancer. 2013;81:319-27.

34. Flores RM, Pass HI, Seshan VE, Dycoco J, Zakowski M, Carbone M, et al. Extrapleural pneumonectomy versus pleurectomy/decortication in the surgical management of malignant pleural mesothelioma: results in 663 patients. $J$ Thorac Cardiovasc Surg. 2008;135:620-6. 626.e621-623.

35. Baldini EH, Richards WG, Gill RR, Goodman BM, Winfrey OK, Eisen HM, et al. Updated patterns of failure after multimodality therapy for malignant pleural mesothelioma. J Thorac Cardiovasc Surg. 2015;149:1374-81.

36. Ploenes T, Osei-Agyemang T, Krohn A, Waller CF, Duncker-Rohr V, Elze M, et al. Changes in lung function after surgery for mesothelioma. Asian Cardiovasc Thorac Ann. 2013;21:48-55.

37. Bedirhan MA, Cansever L, Demir A, Ceyhan S, Akın H, Urer HN, et al. Which type of surgery should become the preferred procedure for malignant pleural mesothelioma: extrapleural pneumonectomy or extended pleurectomy? J Thorac Dis. 2013;5:446-54.

38. Lang-Lazdunski L, Bille A, Lal R, Cane P, McLean E, Landau D, et al. Pleurectomy/decortication is superior to extrapleural pneumonectomy in the multimodality management of patients with malignant pleural mesothelioma. J Thorac Oncol. 2012;7:737-43.

39. Nakas A, von Meyenfeldt E, Lau K, Muller S, Waller D. Long-term survival after lung-sparing total pleurectomy for locally advanced (International Mesothelioma Interest Group Stage T3-T4) non-sarcomatoid malignant pleural mesothelioma. Eur J Cardiothorac Surg. 2012;41:1031-6.

40. Okada M, Mimura T, Ohbayashi C, Sakuma T, Soejima T, Tsubota N. Radical surgery for malignant pleural mesothelioma: results and prognosis. Interact Cardiovasc Thorac Surg. 2008;7:102-6.

41. Sugarbaker DJ, Richards WG, Bueno R. Extrapleural pneumonectomy in the treatment of epithelioid malignant pleural mesothelioma: novel prognostic implications of combined N1 and N2 nodal involvement based on experience in 529 patients. Ann Surg. 2014;260:577-80.

Key Words: malignant pleural mesothelioma, pleurectomy, decortication, hyperthermic intrathoracic chemotherapy 


\section{APPENDIX E1. HYPERTHERMIC \\ INTRATHORACIC INTRAOPERATIVE CHEMOTHERAPY PROTOCOL Inclusion Criteria}

1. Histologic diagnosis of epithelial or biphasic malignant pleural mesothelioma.

2. Clinical International Mesothelioma Interest Group stage I-III.

3. Age between 18 and 75 years.

4. Performance status $<3$ according to Eastern Cooperative Oncology Group scale,

5. Blood analysis:

- Platelets count $>100,000 \mu / \mathrm{L}$

- Hemoglobin level $>10 \mathrm{~g} / \mathrm{dL}$

- White blood cells $>4000 \cdot 10^{3} \mu / \mathrm{L}$

6. Absence of cardiac or neuropathic disease.

7. Absence of concomitant infection.

8. Absence of pregnancy.

\section{Preoperative Evaluation}

1. Blood analysis:

- Hemochromocytometric test (complete blood count)

- Blood chemistry test (glucose, electrolytes)

- Coagulation test (prothrombin time [PT], activated partial thromboplastin time [aPTT], international normalized ratio [INR], fibrinogen, and D-dimer)

- Evaluation of liver and kidney function (serum glutamic oxaloacetic transaminase [GOT], glutamic pyruvic transaminase [GPT], gamma-glutamyl transferase [GGT], albumin, protein electrophoresis, blood urea nitrogen $[\mathrm{BUN}]$, creatinine and creatinine clearance)

2. Cardiac evaluation

- Electrocardiogram

- Echocardiography with ejection fraction evaluation

- Exercise stress test if requested by cardiologist

3. Pulmonary evaluation

- Chest radiograph

- Pulmonary function tests

- Arterial blood gas analysis

- Six-minute walking test if requested by pneumologist

DAY 1

Start sequential hydration 24 hours before the surgery:

- Saline solution $(500 \mathrm{cL})$ with the addition of dexamethasone $(8 \mathrm{mg})$ and ranitidine $(50 \mathrm{mg})$

- Sodium lactate solution $(1000 \mathrm{cL})$

- Saline solution (500 cL) with the addition of furosemide (20 mg)
Antithrombotic prophylaxis with low-molecular-weight heparin (LMWH) according to the patient's weight.

\section{DAY 0 (OPERATIVE DAY)}

Intraoperative monitoring:

- Central venous catheter

- Nasogastric tube

- Urinary catheter

- Arterial pressure monitoring

- Temperature sensor

- Antithrombosis tights

- Isotonic solution

\section{SURGICAL PROCEDURE AND HYPERTHERMIC INTRATHORACIC INTRAOPERATIVE CHEMOTHERAPY}

Complete parietal and mediastinal pleurectomy and a partial decortication sparing the diaphragm and the pericardium is performed with the goal of achieving a macroscopic complete resection. Mediastinal lymph-node sampling is performed. A temperature probe is placed into the pleural cavity. Two 28- or 32-Fr intercostal drains are placed in the pleural space: one at the apex and one on the diaphragm, respectively working as outflow and inflow drainage during the perfusion.

We routinely use Performer LRT (Rand, Medolla, MO, Italy). The patient is left on lateral decubitus with collapsed lung throughout the procedure. First, the chest cavity is filled up through the lower drainage (inflow) with isotonic solution; the correct volume for each patient is assessed according to the body surface $\left(2-2.5 \mathrm{~L} / \mathrm{m}^{2}\right)$. Body surface is calculated with the Mosteller formula. Once the chest cavity is filled, the apical drainage (outflow) is connected and the perfusion is started until the intrathoracic target temperature $\left(42.5^{\circ} \mathrm{C}\right)$ is reached; drugs are then added to the perfusion as a bolus (epirubicin $25 \mathrm{mg} / \mathrm{m}^{2}$ alone and cisplatin $80 \mathrm{mg} / \mathrm{m}^{2}$ in $250 \mathrm{cL}$ of saline solution). Chemotherapy drugs and solutions are prepared in the pharmacy department, and they are sent directly to the operating room in a closed, light-protected bag. From the time drugs are inserted in the circuit, perfusion is run for an additional $60 \mathrm{mi}-$ nutes so that the chest cavity is uniformly exposed to heat and chemotherapy. At the end of the perfusion, inflow and outflow drains are exchanged to empty the pleural space, temperature probes are removed, and lung is ventilated again.

Operative day intravenous hydration and therapies to start during surgery:

- Intravenous ceftriaxone ( $2 \mathrm{~g}$ )

- Saline solution $(500 \mathrm{cL})$ with the addition of dexamethasone $(16 \mathrm{mg})$ and ranitidine $(50 \mathrm{mg})$ 
- Saline solution (500 cL) with the addition of $20 \mathrm{mEq}$ $\mathrm{MgSO}_{4}$

- Saline solution $(500 \mathrm{cL})$ with the addition of $20 \mathrm{mEq} \mathrm{KCl}$

- Saline solution $(500 \mathrm{cL})$ with the addition of furosemide $(20 \mathrm{mg})$

- Sodium lactate solution $(500 \mathrm{cl})$

- Saline solution $(500 \mathrm{cL})$ with the addition of furosemide (20 mg)

Antithrombotic prophylaxis is performed with LMWH according to the patient's weight.

Elastomeric infusion pump for the administration of continuous intravenous analgesia (morphine up to a maximum of $30 \mathrm{mg}$ ); additional analgesic therapy is available by the patient's request (paracetamol $1000 \mathrm{mg}$ or ketorolac $75 \mathrm{mg}$ ).

Postoperative blood analysis:

- Hemochromocytometric test (complete blood count)

- Blood chemistry test (glucose, electrolytes)

- Coagulation test (PT, aPTT, INR, fibrinogen, D-dimer)

- Evaluation of liver and kidney function (GOT, GPT, GGT, albumin, BUN, creatinine)

\section{DAYS 1 TO 5 (POSTOPERATIVE DAYS)}

Hydration and therapies:

- Ceftriaxone (2 g)

- Saline solution $(500 \mathrm{cL})$ with the addition of dexamethasone $(4 \mathrm{mg})$ and ranitidine $(50 \mathrm{mg})$

- Sodium lactate solution (1000 cL)

- Saline solution $(500 \mathrm{cL})$ with the addition of furosemide (20 mg)

Antithrombotic prophylaxis with LMWH according to the patient's weight.

Elastomeric infusion pump for the administration of continuous intravenous analgesia.

Daily blood analysis:

- Hemochromocytometric test (complete blood count)

- Blood chemistry test (glucose, electrolytes)

- Coagulation test (PT, aPTT, INR, fibrinogen, D-dimer)

- Evaluation of liver and kidney function (GOT, GPT, GGT, albumin, BUN, creatinine)

Mobilization from the first postoperative day.

Chest radiograph on day 0-2-5 or when required for clinical conditions. 